\title{
Endoscopic injection therapy for bleeding peptic ulcer; a comparison of adrenaline alone with adrenaline plus ethanolamine oleate
}

\author{
C P Choudari, K R Palmer
}

\begin{abstract}
One hundred and seven consecutive patients presenting with significant peptic ulcer haemorrhage were randomised to endoscopic injection with 3-10 ml of 1:100 000 adrenaline (55 patients, group 1) or to a combination of adrenaline and $5 \%$ ethanolamine (52 patients, group 2). All had major stigmata of haemorrhage and endoscopic injection was undertaken by a single endoscopist. The groups were well matched with regard to risk factors. Rebleeding occurred in eight of the group 1 patients and seven in the group 2 patients; surgical operation rates, median blood transfusion requirements, and hospital stay were similar in both groups. The efficacy of either form of injection was similar whether patients presented with active bleeding or a nonbleeding visible vessel. No complications occurred. In patients presenting with significant peptic ulcer bleeding, the addition of a sclerosant confers no advantage over injection with adrenaline alone.

(Gut 1994; 35: 608-610)
\end{abstract}

The prognosis of patients presenting with significant bleeding from peptic ulcer is improved by endoscopic injection therapy, but the best injection regimen is unclear. Chung et al have shown that injection with 1:10000 adrenaline alone stops active bleeding in most cases, although rebleeding rates were not reported. ${ }^{1}$ Wardehoff and $\mathrm{Gros}^{2}$ showed that injection of the sclerosant polidocanol reduces the risk of rebleeding in patients presenting with major stigmata of recent haemorrhage, but the efficacy of sclerosants alone as treatment for active bleeding is less clear. Other groups ${ }^{3-5}$ have used combination injection therapy based upon the hypothesis that the vacoconstricting action of an initial adrenaline injection stops active bleeding and localises a subsequent sclerosant injection; because the effects of adrenaline will probably be short lived, a sclerosant is then injected to promote arterial thrombosis and prevent rebleeding.

In experimental animals an intramucosal injection of adrenaline effectively arrested active haemorrhage from gastric mucosal wounds, while various sclerosants actually exacerbated bleeding. ${ }^{6}$ In the experimental situation, both $5 \%$ ethanolamine and ethanol injections induced a vigorous local inflammatory reaction associated with venous thrombosis, but endarteritis and arterial thrombosis were not seen ${ }^{6}$ Although this approach affects non-ulcerated mucosa, conflicts with findings in a canine model of gastrointestinal bleeding, ${ }^{7}$ and is comparatively far removed from the clinical problem of haemorrhage from a chronic peptic ulcer, these experiments question the value of sclerosant injections. Furthermore the potential risk of ulcer enlargement or performation that could follow the use of sclerosants, demands proof that sclerosant injections are necessary in the endoscopic treatment of bleeding peptic ulcers. We have therefore conducted a clinical study in patients presenting with major peptic ulcer haemorrhage to find out if the addition of a sclerosant to injection therapy with dilute adrenaline confers any clinical value over an injection of adrenaline alone. It is well established that the most important prognostic factors include the endoscopic findings of active haemorrhage or the presence of a non-bleeding viable vessel within the ulcer bed. ${ }^{89}$ These findings are associated with different degrees of risk; about $80 \%$ of patients who present with active, arterial bleeding continue to bleed or rebleed, while about $50 \%$ of those with a nonbleeding vessel will rebleed. It is conceivable that the haemostatic response to adrenaline or adrenaline plus a sclerosant differs between these groups and the response to endoscopic treatment was therefore studied in relation to the endoscopic findings.

\section{Patients and methods}

\section{DESIGN AND INCLUSION CRITERIA}

Between November 1991 and September 1992, consecutive patients presenting with significant peptic ulcer haemorrhage were considered for inclusion into the study. These patients presented to the four main admitting units of the Lothian region of Scotland (St John's Hospital, Livingston, Royal Infirmary of Edinburgh, Eastern General Hospital, Edinburgh, and the Western General Hospital, Edinburgh). After resuscitation endoscopy was performed by a single operator (CPC) under benzodiazepine sedation using an Olympus XQ10 forward viewing gastroscope. Patients who were found to have a peptic ulcer that was either actively bleeding or contained a non-bleeding visible vessel were included in the study if they had one other clinical risk factor. These risk factors were age over 60 years, initial haemoglobin concentration less than $10 \mathrm{~g} / \mathrm{dl}$ or shock, defined as a pulse rate greater than 100 beats/min or a systolic blood pressure less than $100 \mathrm{~mm} \mathrm{Hg}$, or both. A history of non-steroidal anti-inflammatory drug (NSAID) use and evidence of significant cardiorespiratory disease was recorded. All patients received injection therapy with $1: 100000$ adrenaline and were then randomised by open-
Western General

CP P Choudari

K R Palmer

Correspondence to: Dr K R Palmer, Consultan Physician, GI Annexe, Edinburgh EH4 2XU.

Accepted for publication 20 September 1993 
ing a sealed envelope to receive either no additional injection therapy (group 1) or a further injection of $5 \%$ ethanolamine oleate (group 2 ).

\section{ENDOSCOPIC TECHNIQUE}

Injections were given using a disposable $4 \mathrm{~mm}$, 23 gauge injection needle (Keymed Ltd, Southend upon Sea, UK). Multiple injections (each of 0.5 to $1.5 \mathrm{ml}$ ) of $1: 100000$ adrenaline were injected into and around the bleeding vessel to a total volume of 3-12 $\mathrm{ml}$ (median $7 \cdot 5 \mathrm{ml}$ ). In patients randomised to group 2, a total of 0.2 $2.0 \mathrm{ml} 5 \%$ ethanolamine was then injected into the vessel.

\section{FOLLOW UP}

Patients with active bleeding at presentation and those in which initial treatment was thought suboptimal had repeat endoscopic therapy within 24 to 48 hours. After endoscopy all patients received histamine receptor antagonist drugs in standard doses. Subsequent management decisions were left to admitting physicians and surgeons who were unaware of the randomised endoscopic treatment. The following end points were determined: (1) Rebleeding, defined as fresh haematemesis or malaena, or both with either shock (pulse rate greater than 100 beats/ $\mathrm{min}$, systolic blood pressure less than $100 \mathrm{~mm}$ of $\mathrm{Hg}$ ) or a fall in haemoglobin concentration of at least $2 \mathrm{~g} / \mathrm{dl}$ over a 24 hour period. Rebleeding was in every case confirmed either endoscopically by the presence of fresh blood in the upper gastrointestinal tract or by emergency surgery. (2) Surgical operation. The decision to perform a surgical operation (similar to all management decisions) was left entirely to the admitting team. Rebleeding was the only indication for surgery. (3) Units of blood transfused. (4) Duration of hospital admission. (5) Thirty day mortality (from the time of admission).

TABLE I Patient characteristics

\begin{tabular}{|c|c|c|c|c|}
\hline & \multicolumn{2}{|l|}{$\begin{array}{l}\text { Adrenaline } \\
\text { (group } 1=55)\end{array}$} & \multicolumn{2}{|c|}{$\begin{array}{l}\text { Adrenaline }+5 \% \text { ethanolamine } \\
\text { (group 2=52) }\end{array}$} \\
\hline & $\begin{array}{l}\text { Active bleeding } \\
(n=29)\end{array}$ & $\begin{array}{l}\text { Non-bleeding } \\
\text { vessel }(n=26)\end{array}$ & $\begin{array}{l}\text { Active bleeding } \\
(n=28)\end{array}$ & $\begin{array}{l}\text { Non-bleeding } \\
\text { vessel }(n=24)\end{array}$ \\
\hline $\begin{array}{l}\text { Median age, (range) years } \\
\text { Sex }(M: F)\end{array}$ & $\begin{array}{l}69 \cdot 0(23-93) \\
19: 10\end{array}$ & $\begin{array}{l}67 \cdot 5(32-89) \\
19: 7\end{array}$ & $\begin{array}{l}71 \cdot 5(37-92) \\
15: 13\end{array}$ & $\begin{array}{l}66 \cdot 0(23-95) \\
15: 9\end{array}$ \\
\hline $\begin{array}{l}\text { Mean admission haemoglobin } \\
\text { concentration }(\mathrm{SD}), \mathrm{g} / \mathrm{dl} \\
\text { Number in shock } \\
\text { NSAID users } \\
\text { Gastric ulcers } \\
\text { Duodenal ulcers }\end{array}$ & $\begin{array}{l}8 \cdot 2(2 \cdot 1) \\
17 \\
8 \\
12 \\
17\end{array}$ & $\begin{array}{l}8 \cdot 7(2 \cdot 2) \\
15 \\
11 \\
13 \\
13\end{array}$ & $\begin{array}{l}9 \cdot 2(1 \cdot 6) \\
17 \\
13 \\
9 \\
19\end{array}$ & $\begin{array}{l}9 \cdot 2(2 \cdot 1) \\
11 \\
7 \\
10 \\
14\end{array}$ \\
\hline
\end{tabular}

NSAID $=$ non-steroidal anti-inflammatory drug.

TABLE II Results of treatment

\begin{tabular}{|c|c|c|c|c|}
\hline & \multicolumn{2}{|l|}{$\begin{array}{l}\text { Adrenaline } \\
\text { (group I) }\end{array}$} & \multicolumn{2}{|c|}{$\begin{array}{l}\text { Adrenaline }+5 \% \text { ethanolamine } \\
\text { (group 2) }\end{array}$} \\
\hline & $\begin{array}{l}\text { Active bleeding } \\
(n=29)\end{array}$ & $\begin{array}{l}\text { Non-bleeding } \\
\text { vessel }(n=26)\end{array}$ & $\begin{array}{l}\text { Active bleeding } \\
(n=28)\end{array}$ & $\begin{array}{l}\text { Non-bleeding } \\
\text { vessel }(n=24)\end{array}$ \\
\hline Number rebleeding & 7 & 1 & 6 & 1 \\
\hline Number retreated & 5 & 1 & 5 & - \\
\hline Permanent haemostasis & 25 & 26 & 25 & 23 \\
\hline Emergency surgery & & - & & \\
\hline Median units transfused (range) & $5(0-13)$ & $4(0-12)$ & $4(0-12)$ & $4(0-7)$ \\
\hline $\begin{array}{l}\text { Median duration of admission } \\
\text { (range), days }\end{array}$ & $7(3-76)$ & $6 \cdot 5(3-16)$ & $7(3-30)$ & $6(3-20)$ \\
\hline $\begin{array}{l}\text { (range), days } \\
\text { Hospital mortality }\end{array}$ & - & 1 & - & - \\
\hline
\end{tabular}

\section{POLICY AFTER REBLEEDING}

Rebleeding was treated either by a surgical operation or (if requested by the admitting team) by endoscopic therapy. Endoscopically treated rebleeding patients received the same form of endoscopic treatment as was given at the time of admission.

\section{STATISTICAL ANALYSIS}

Differences in outcome were analysed using the $\chi^{2}$ test.

\section{ETHICAL CONSIDERATIONS}

The study was approved by the ethics of medicine and oncology committee of the Lothian Health Board. Where possible written consent was obtained from each subject. Otherwise permission was obtained from a relative or in rare circumstances, retrospectively.

\section{Results}

Of 254 patients undergoing emergency endoscopy for acute gastrointestinal haemorrhage during the period of study, 107 were randomised. Five patients who were actively bleeding from peptic ulcers were not included because the bleeding point was not identified or initial haemostasis could not be achieved by adrenaline and a further two patients were excluded because their ulcers were inaccessible to injection; three of these subsequently died.

Table I shows the characteristics of the randomised patients. The two groups were well matched with regard to age, sex, ulcer type, and the major risk factors for rebleeding (initial haemoglobin concentration, shock, and endoscopic stigmata).

Table II shows no significant difference in rebleeding rates in the two groups, although the 95\% confidence limits for the odds ratio for rebleeding in patients treated with adrenaline $v$ combination therapy are wide $(0.32$ to 4.03$)$. Eight group 1 patients (14.5\%) and seven group 2 patients $(13 \cdot 5 \%)$ rebled during their hospital admission. Most of these had initially presented with active bleeding rather than a non-bleeding visible vessel. Six group 1 patients who rebled received a further injection of adrenaline and permanent haemostasis was achieved in four. Five group 2 patients who rebled were treated with further combination injection therapy and three responded.

These eight patients who continued to bleed despite endoscopic therapy had emergency surgery and all recovered.

Transfusion requirements and duration of admission were similar in both groups and no significant differences emerged in relation to the initial endoscopic stigmata. One patient died from myocardial infarction eight days after apparently successful endoscopic therapy; an autopsy showed no evidence of rebleeding.

No significant complications followed endoscopic therapy. Bleeding was induced by injection treatment of non-bleeding protuberant vessels in six patients (12\%) but was invariably controlled by a further injection of adrenaline. 


\section{Discussion}

This study of patients presenting with significant endoscopic stigmata of bleeding from peptic ulcers, shows that combination injection treatment with dilute adrenaline and the sclerosant $5 \%$ ethanolamine had similar efficacy to an injection of adrenaline alone. As expected patients who presented with active arterial bleeding initially responded less well than those with a non-bleeding visible vessel, but in most of the patients who rebled permanent haemostasis was eventually achieved by a second injection using the same agents as had been used at the index endoscopy. For ethical reasons we did not include a control group having previously shown that conservatively managed patients presenting with the major endoscopic stigmata of active haemorrhage or a non-bleeding protuberant vessel, have about a $50 \%$ risk of continued bleeding or rebleeding. ${ }^{5}$ Many endoscopists have used adrenaline concentrations of 1:10000 while we have used a concentration of 1:100000 because of concerns relating to an increase in circulating adrenaline concentrations. Despite this difference our rebleeding rate in injected patients of $15 \%$ is very comparable with that previously described by ourselves in a similar patient group ${ }^{5}$ and similar to that reported by others in clinical trials. ${ }^{34}$

Our study included a selected subgroup of patients. The entry criteria defined high risk subjects, but the most severe cases comprising patients with very severe active haemorrhage in whom the bleeding site was not identified or not controlled by adrenaline injection were excluded. These patients can be considered to represent failures of adrenaline injection and it is conceivable that haemostasis could have been effected by the addition of a sclerosant injection. In four patients this was impossible because massive bleeding obscured the bleeding site and prevented injection; the diagnosis of peptic ulcer haemorrhage was made at surgical operation. In one patient active, arterial peptic ulcer bleeding was seen but the severity of bleeding and cardiovascular instability suggested that after a difficult, incomplete, and unsuccessful adrenaline injection a surgical operation represented the wisest treatment. The remaining failures of adrenaline injection were two subjects in whom inaccessibility due to anatomical deformity prevented injection. These failures do not detract from our conclusions, however, as the particular aim was to define the role of sclerosants in the prevention of rebleeding; there is little evidence that sclerosants have a role in acute haemostasis.

Our conclusions are at variance with the findings of some studies suggesting that small volumes of ethanol stop active peptic ulcer bleeding. ${ }^{10-12}$ Most of these studies contain small numbers of patients or are uncontrolled, yet it is difficult to explain this trend in relation to our own findings. It is possible that the mechanism of haemostasis associated with ethanol (principally tissue dehydration) is different to that assumed for ethanolamine (endarteritis and thrombosis), but our own studies in experimental animals suggested that neither agent reliably caused arterial thrombosis. ${ }^{6} \mathrm{~A}$ further study also suggested that a combination of adrenaline and polidocanol was a more effective modality than adrenaline alone, ${ }^{13}$ but the number of subjects was small and this trend did not achieve statistical significance.

In common with other published series, rebleeding rates were low in both study groups. As a result our study has limited power to detect a modest difference in efficacy between the two treatment regimens and our data do not unequivocally show that the addition of ethanolamine is of no clinical value. We can only state that if ethanolamine injection does confer additional benefit, this must be of extremely limited clinical value.

Our conclusions support the view of the group from Hong Kong ${ }^{1}$ that injection therapy with dilute adrenaline leading to vasoconstriction possibly followed by arterial thrombosis is the most important therapeutic measure. Sclerosants should be avoided because they do not further reduce rebleeding rates and carry the risk of mucosal damage and ulcer complications. Our own policy is now to use $1: 100000$ adrenaline without the addition of sclerosants as injection therapy for patients presenting with important endoscopic stigmata and peptic ulcer haemorrhage.

Supported by grant from Scottish Hospital Endowments Research Trust. This work is published in abstract form in Gut 1993; 34 (suppl): \$30.

1 Chung SCS, Leung JWC, Steele RJC, Crofts TJ, Li AKC. Endoscopic injection of adrenaline for actively bleeding Endoscopic injection of adrenaline for actively

2 Wordehoff D, Gros H. Endoscopic haemostasis by injectiontherapy in high-risk patients. Endoscopy 1982; 14: 196-9.

3 Panes J, Viver J, Forne M, Garcia-Olivares E, Marco C, Garan $\mathrm{J}$. Controlled trial of endoscopic sclerosis in bleeding peptic ulcers. Lancet 1987; ii: 1292-4.

4 Balanzo J, Sainz S, Such J, Espinos JC, Guarner C, Cusso X, et al. Endoscopic haemostasis by local injection of adrenaline and polidocanol in bleeding ulcer. A prospective randomised trial. Endoscopy 1988; 20: 289-91.

5 Rajgopal C, Palmer KR. Endoscopic injection sclerosis: effective treatment for bleeding peptic ulcer. Gut 1991; 32 : 727-9.

6 Rajgopal C, Lessels A, Palmer KR. Mechanism of action of injection therapy for bleeding peptic ulcer. Br F Surg 1992; 79: $782-4$.

7 Rutgeerts P, Geboes K, Vantrappen G. Experimental studies of injection therapy for severe non-variceal bleeding in dogs. Gastroenterology 1989; 97: 610-21.

8 Storey DW, Bown SG, Swain CP, Salmon PR, Kirkham JS, Northield TC. Endoscopic prediction of recurrent bleeding in peptic ulcers. $N$ Engl F Med 1981; 305: 915-6.

Therapeutic endoscopy and bleeding ulcers - NIH concensus conference. FAMA 1989; 262: 1369-72.

10 Sugawa C, Fujita Y, Ikeda T, Walt AJ. Endoscopic haemostasis of bleeding of the upper gastrointestinal tract by local injection of $98 \%$ dehydrated ethanol. Surg Gynecol Obstet 1986; 162: 159-63.

11 Pascu O, Draghici A, Acalovchi I. The effect of endoscopic haemostasis with alcohol on the mortality rate of nonvariceal upper gastrointestinal haemorrhage. A randomised variceal upper gastrointestinal haemorrhage.

12 Lazo MD, Andrade R, Medina MC, Garcia-Fernandez G, Sanchez-Cantos AM, Franquelo E. Effect of injection sclerosis with alcohol on the rebleeding rate of gastroduodenal peptic ulcers with non-bleeding visible vessels. A prospective, controlled trial. Am F Gastroenterol 1992; 87 843-6.

13 Rutgeerts P, Vantrappen G, Broekaert L, Coremans G, Janssens HJ, Miele M. Comparison of endoscopic polidocanol injection and YAG laser therapy for bleeding peptic ulcers. Lancet 1989; i: 1164-7. 